\title{
Democracia local y ciudadanía Estado del arte: organizaciones del tercer sector
}

\author{
Marcelo Torres Fuentes*
}

\section{RESUMEN}

Lo central del artículo es realizar una reflexión teórica actualizada respecto de las Organizaciones del Tercer Sector (OTS), tipologías, sus características, finalidades y las tendencias preliminares del estudio.

La vinculación del tema en cuestión con el Trabajo Social, se da fundamentalmente en que uno de los principales espacios laborales de nuestra profesión es en este tipo de organizaciones, que son las encargadas de ejecutar dentro de sus tantas finalidades la política social. Por tanto, conocer a este tipo de organizaciones nos permite observar los campos laborales en los cuales se sitúa la intervención social.

Palabras clave: Organizaciones del tercer sector / Sociedad civil / ciudadanía / Trabajo Social.

\section{Democracia local e ciudadania Estado da arte: organizações do terceiro sector}

\begin{abstract}
O central do artigo é realizar uma reflexão teórica actualizada respecto das Organizações do terceiro Sector (OTS), tipologías, suas características, finalidades e as tendências preliminares do estudo.

A vinculación do tema em questão com o Trabalho Social, dá-se fundamentalmente em que um dos principais espaços trabalhistas de nossa profissão é neste tipo de organizações, que são as encarregadas de executar dentro de suas tantas finalidades a política social. Por isso, conhecer a este tipo de organizações nos permite observar os campos trabalhistas nos quais se situa a intervenção social.
\end{abstract}

Palavras chave: Organizações do terceiro sector / Sociedade civil / cidadania / Trabalho Social.

* Chileno. Trabajador Social. Magíster en Políticas Sociales y Gestión Local. Docente Escuela de Trabajo Social Universidad Católica Silva Henríquez y Universidad Central de Chile. Correo electrónico: martrabsocial@gmail.com 


\section{Local democracy and citizenship state of the art: organizations of the third sector}

\section{ABSTRACT}

The central of the article, is realizes a theoretical updated reflection respect of the Organizations of the third Sector (OTS), topic, his characteristics, purposes and the preliminary trends of the study.

The entail of the topic in question with the Social Work, is given fundamentally in that one of the principal labor spaces of our profession is given in this type of organizations, that are the managers of executing inside his so many purposes the social politics.Them, to know to this type of organizations, allows us to know the labor fields in which the social intervention places.

Key words: Organizations of the third sector / Civil society / citizenship / Work Social. 


\section{Antecedentes sociopolíticos}

Chile es un país que en los últimos años ha vivido grandes transformaciones tanto en lo social, político, tecnológico y en lo económico. Estos avances han sido más intensos con el retorno de la democracia en 1990, donde se da inicio a un período de sucesivos cambios sociales, donde el estado como representante del sector público ha asumido un rol relevante ante las complejas situaciones heredadas de la dictadura militar.

Esta estrategia de los Gobiernos de la Concertación persigue el logro de un crecimiento equitativo y sustentable, con el fin de mejorar la calidad de vida de la población, en aquellos sectores más postergados. Bajo los gobiernos democráticos se da inicio al Proyecto de Reforma y Modernización del Estado, que es la expresión del propósito de avanzar resueltamente en la construcción de un Estado al servicio de los ciudadanos. El diseño de este proyecto se inspira en los principios de la transparencia, la eficiencia, la equidad y la participación, como base principal para el funcionamiento de un Estado democrático.

De esta manera, surge la necesidad de dar inicio a un proceso modernizador, sentando las bases de un trabajo con objetivos y metas claras, el que pretende ser ejercido con eficacia y eficiencia, en pro del desarrollo del país y de los ciudadanos. Uno de los ejes centrales de acción ha sido el tema de la participación. Para esto se ha buscado el sustento de una democracia más extendida, eficaz y flexible, que apunte a reforzar la sociedad civil a nivel regional y local, como un factor clave para el desarrollo del país, a través de una política social cuya función se enmarca, no solo en una herramienta orientada a los grupos más vulnerables, sino que más bien, debe estar acompañada de un capital humano y organizacional que sea capaz de gestionar su propia integración.

Sin embargo, esta nueva forma de hacer gestión ha exigido cambios trascendentales en el sector público, orientando su accionar a una mayor participación de todos los sectores de la sociedad, donde el espacio local cobra relevancia, al constituirse en el lugar fundamental para el desarrollo del país. Es en este espacio donde las comunidades progresan y se desarrollan en sus distintas dimensiones. Por esto, el desarrollo local, adquiere una real importancia en el proceso de planificación a nivel territorial, lo que es concebido como un instrumento fundamental de carácter orientador y conductor respecto a las soluciones propuestas 
como estrategias de la superación de la pobreza. Esto significa vincular el gobierno con las personas, para una mayor eficiencia en la entrega de los bienes y servicios dirigidos a la comunidad, en las áreas de coordinación interinstitucional, descentralización, participación e información.

En este contexto la División de Coordinación Interministerial del Ministerio Secretaría General de la Presidencia, señala que entre los años 2000 y 2004, ha promovido la participación ciudadana basándose en cinco ejes orientadores: buen trato; transparencia de la gestión pública; igualdad de oportunidades para la participación; respeto a la autonomía y diversidad de las organizaciones de la sociedad civil; y orientación al ciudadano.

Por otro lado, el Banco Interamericano de Desarrollo, aprobó el "Programa para fortalecer alianzas entre la sociedad civil y el Estado" (PROFASCE), que fue ejecutado entre el 2001 y el 2004 por el Ministerio Secretaría General de Gobierno, a través de la División de Organizaciones Sociales. Su objetivo fue apoyar la generación de condiciones propicias para que la ciudadanía participe más activamente en el diseño y ejecución de acciones dirigidas al bienestar común. En términos institucionales, el proyecto permitió poner en marcha una política nacional y transversal de participación ciudadana coordinada por la Secretaría General de Gobierno.

En términos más específicos, el proyecto se orientó a los siguientes objetivos:

- Aumento del número de las Organizaciones de la Sociedad Civil (OSC) con autosuficiencia operativa y financiera.

- Incremento en niveles de participación en al menos 20 programas priorizados y mejora en percepción de usuarios respecto a la participación ciudadana.

- Sociedad sensibilizada en una cultura de cooperación. Aumento en el número de voluntarios e instituciones dedicadas al voluntariado.

- Creación de espacios de interlocución y comunicación que generaran diálogo entre el Estado y la sociedad civil.

En materia de fortalecimiento de la sociedad civil, en mayo de 2001 se implementó el "Plan para el fortalecimiento de las organizaciones de la sociedad civil", documento a través del cual el Presidente de la República acoge un conjunto de propuestas formuladas en materia de participación ciudadana, 
por una comisión integrada por representantes de la sociedad civil y autoridades gubernamentales. En lo medular, este plan contempla medidas en cinco áreas temáticas: desarrollo de un marco jurídico; financiamiento; fortalecimiento institucional de las organizaciones; promoción del trabajo voluntario; y cooperación entre el Estado y la sociedad civil, en directa relación con la ejecución del Instructivo Presidencial de Participación Ciudadana.

A partir de un proceso de consulta a organizaciones de todas las regiones del país, se formuló el Proyecto de Ley de Participación Ciudadana, ingresado a trámite parlamentario el 8 de junio de 2004. La iniciativa establece modificaciones al marco jurídico sobre organizaciones de la sociedad civil, y aspectos de la administración pública. Con respecto al primer aspecto, crea el registro de organizaciones de interés público y el fondo para el desarrollo de la sociedad civil que permitirá que los recursos del Estado sean distribuidos con crecientes niveles de control y participación de los y las ciudadanas; se reforma la legislación sobre juntas de vecinos y demás organizaciones comunitarias y se propone modificaciones a la constitución legal, causales de extinción, reconocimiento de redes y federaciones; se legaliza la ausencia de fines de lucro en las organizaciones y se establece un estatuto para el trabajo voluntario.

Este cuerpo legal recoge la propuesta ciudadana formulada durante el año 2003, con seis mil representantes de organizaciones en 71 talleres comunales y 13 encuentros regionales. De este trabajo derivó una propuesta de fortalecimiento institucional y de modalidades de financiamiento para las organizaciones de la sociedad civil.

Los avances en materia de fortalecimiento de la sociedad civil emanados de la propuesta del Consejo Ciudadano, son los siguientes:

- Formación del Consejo del Fondo para el Fortalecimiento de la Sociedad Civil: Integrado por representantes del mundo asociativo nacional y público. Esta instancia vela por la transparencia de los procesos de asignación de recursos para las organizaciones sociales, y realiza un seguimiento al cumplimiento del Plan de fortalecimiento de la sociedad civil.

- Fondo Provisorio para el Fortalecimiento de la Sociedad Civil: Se implementó el Fondo de Capacitación para Organizaciones 
Sociales, orientado al fortalecimiento institucional y de gestión, a través del financiamiento de proyectos que favorezcan la conformación de redes asociativas en el seno de la sociedad civil. En el año 2003, un fondo de 630 millones de pesos articuló la demanda social con la oferta organizada en una Guía Nacional de Capacitación con 1.041 cursos. Ello permitió que 3 mil 649 representantes de organizaciones comunitarias -territoriales y funcionales- fueran capacitados en 177 cursos y programas de capacitación a nivel nacional. A fines de 2003 e inicios de 2004, este Fondo entregó 733 millones de pesos para financiar proyectos de asistencia técnica para organizaciones sociales y encuentros nacionales, regionales y locales. Esta iniciativa benefició a más de 6 mil organizaciones, e indirectamente alcanzó a más de 280 mil personas.

- Se puso en funcionamiento el primer Registro Único de Organizaciones Colaboradoras del Estado y las Municipalidades, que constituye un sistema público de todas las organizaciones que reciben o quieren postular a recibir fondos públicos. Quienes lo deseen podrán acreditarse bajo la figura de organizaciones de interés público, cuando sus fines promuevan valores básicos o trabajen temáticas sociales. Con esto podrán crear sus propios sitios web y cuentas de correo electrónico, disponer de información permanente sobre fondos y programas sociales para organizaciones, visualizar sus experiencias y proyectos, entre muchas otras prestaciones.

- Se puso en funcionamiento el sitio web www.portalciudadano. $\mathrm{cl}$ : Con el objeto de que las organizaciones cuenten con un canal efectivo de información gubernamental atingente, así como para promover la interactividad y la participación de las diversas expresiones asociativas de la sociedad civil en una comunidad virtual, visibilizando sus respectivos trabajos y generando asociatividad entre ellas, a través del uso de nuevas tecnologías. Este sitio está orientado a organizaciones que se hayan inscrito en el Registro Único de Colaboradores del Estado, y que se hayan autodenominado de interés público, en cuyo caso deben inscribirse en el sitio portal ciudadano, para acceder a la oferta de este sitio.

Para fortalecer el trabajo voluntario en Chile se llevó a cabo un programa piloto con cuatro centros regionales de voluntariado evaluados y con documentación sistematizada. Los centros, ubicados en las regiones IV, V, VIII y Metropolitana, acogieron a 6 mil 778 voluntarios/as, entregaron formación a 5 mil voluntarios/ as y derivaron a 4 mil 414 personas a instituciones de trabajos 
voluntarios. Como parte de sus actividades, los centros regionales financiaron 251 proyectos solidarios por un monto de más de 430 millones de pesos.

Ampliando la iniciativa de los centros regionales del programa Piloto, el año 2004, 119 proyectos de acciones voluntarias fueron desarrollados por organizaciones sociales en todas las regiones del país, con un financiamiento de más de 600 millones de pesos.

El 2003 se realizó el Encuentro Internacional de Voluntariado "Movilizando el Capital Social y el Voluntariado en América Latina", que congregó a 3 mil 500 delegados chilenos y extranjeros en torno al análisis de las perspectivas del voluntariado en la región.

Con el objeto de diseñar una estrategia nacional de voluntariado que promueva una política pública en la materia, se realizaron los siguientes diagnósticos:

- Estudio comparado sobre la situación del voluntariado en Chile y en otros países, publicado y distribuido en todo el país.

- Investigación sobre la conversación social y opinión pública sobre el voluntariado en Chile. Catastro de organizaciones voluntarias en Chile.

A partir de esta experiencia se desarrolló una propuesta de estrategia nacional de fomento de la acción voluntaria como una forma de participación ciudadana y se incorporó un estatuto de voluntariado en el proyecto de ley de participación ciudadana.

En lo referente a la mejora de los canales de comunicación entre el Estado y las personas, se han desarrollado los siguientes progresos:

- Diseño y puesta en funcionamiento de www.chileparticipa. gov.cl, que permite a la ciudadanía conocer y acceder a toda la oferta de beneficios sociales del Estado y sus instituciones dependientes, así como a las oportunidades de participación ciudadana promovida por el instructivo presidencial.

- Desde la propia dinámica de las OTS, se puede mencionar desde un punto de vista cuantificable, basándose en el estudio de Irarrázabal (2006), que el sector sin fines de lucro es un importante actor en la economía chilena, pues de acuerdo a las estimaciones realizadas, el sector no lucrativo 
chileno emplea en forma remunerada y voluntaria sobre las 303 mil personas en jornada completa. Si solo se considera el empleo remunerado, éste representa al $2.6 \%$ de la población económicamente activa.

- También se puede expresar el tamaño relativo del sector en términos de gastos, donde las instituciones sin fines de lucro representan un 1,5\% del PIB, es decir, US\$ 1.408 .9 millones en gastos, solo desde el tercer sector. Chile constituye el mayor sector sin fines de lucro de Latinoamérica, es decir, el sector sin fines de lucro chileno no sólo es significativamente grande comparado con la industria doméstica, como minería, sino también en comparación con los países vecinos y globalmente.

El total del empleo está predominantemente utilizado por el sector de servicios, correspondiente a los dos tercios (59\%) del empleo total (empleo remunerado más voluntariado) del sector sin fines de lucro chileno se encuentran en cuatro campos de actividad relacionados tradicionalmente con el bienestar social: educación, servicios sociales, desarrollo comunitario y salud.

En nuestro país la principal fuente de ingresos está constituida por las subvenciones y los pagos del sector público, alcanzando el $46 \%$ de los ingresos. Este nivel duplica lo que ocurre en países en desarrollo (23\%) y es más cercano a lo que se da en países de tipo europeo de Estado de bienestar (55\%). Las subvenciones de educación, así como los fondos concursables y otras subvenciones específicas del Estado a las OSFL, tienen la característica de ser contratos formales para la entrega de ciertos servicios sujetos a estándares de calidad y cantidad. En estos casos, estas instituciones operan más bien como prestadoras de servicios que como entes autónomos que desean colaborar al desarrollo de grupos o personas desde su propia visión.

Ingresos propios significativos: Son ingresos provenientes de cuotas de membresía y pago por servicios, que también son una fuente importante de ingresos, alcanzando el 36\% de ellos. En términos generales, estos ingresos son la principal fuente de financiamiento en Latinoamérica, llegando a un promedio de 68\%.

También podemos señalar la limitada financiación procedente de la filantropía: la filantropía privada no es la principal fuente de ingresos del sector no lucrativo en ningún país o región. En Chile las donaciones de personas y empresas representan el $18 \%$ de los ingresos de este sector, lo que está a la par con el promedio 
de los países desarrollados (17\%), y son significativamente más altos que en el resto de Latinoamérica (12\%).

Otro dato importante es que son organizaciones con alta presencia de empleo remunerado y alta concentración de los ingresos totales. Las OSFL que se dedican a la educación y las que se dedican a los servicios sociales acumulan el $70 \%$ del empleo remunerado del sector y, a su vez, concentran el 57\% de los ingresos totales del sector.

En definitiva, se trata de organizaciones profesionalizadas que movilizan un volumen importante de recursos. La Región Metropolitana acumula cerca del 50\% del total nacional de las OTS. En términos de empleo remunerado, el 35\% de éste se encuentra en la zona metropolitana, mientras que la población económicamente activa se encuentra en un $43 \%$ en la misma zona.

Por último las fundaciones y corporaciones dominan los ingresos y el empleo remunerado. El personal remunerado de este estatus jurídico alcanza a las 117 mil personas en jornada completa, esto corresponde a un $71 \%$ del total de empleados en el sector sin fines de lucro. De igual manera, estas organizaciones aportan el $60 \%$ de los ingresos; sin embargo, en términos de número de instituciones representan solo el $12 \%$ del total y los voluntarios que se desempeñan en ellas llegan al 11\%. Esto demuestra que este segmento corresponde a las organizaciones que presentan una estructura más grande, formal y sólida, lo que permite que solo unas pocas tengan una gran representatividad dentro del total.

De acuerdo a la información recolectada y al aporte de estas organizaciones en nuestro país, se hace necesario poder conocer desde un punto de vista teórico qué se entiende por OTS, sus características, funciones, entre otros atributos propios de este tipo de actores, como instancias de representación ciudadana, capaces de generar procesos que aportan al desarrollo del territorio. Y más aún, donde en estos espacios se potencia el desarrollo del trabajo social.

Este último aspecto permite relevar su rol, pues a partir de estas ideas se intenta entender la lógica de funcionamiento de este tipo de organizaciones, comprender los posibles campos de actuación profesional, y las implicancias y desafíos de situarse profesionalmente en estos espacios de representación ciudadana que en ocasiones genera ciertos quiebres que se deben asumir a la hora de interactuar en ellas. 


\section{Emergencia del tercer sector}

En el contexto de lo anterior, se ha otorgado una mayor importancia al predominio entre la relación del Estado y el mercado, entre lo político y lo económico, "más bien lo que hemos vivido es una presencia creciente del Estado en todos los ámbitos sociales y económicos y un rol central de los partidos políticos como intermediarios entre los habitantes y el Estado, generando organizaciones sociales débiles y poco representativas." (Serrano 2008:3)

En el artículo citado con anterioridad, se señala que en los años 1998 y 1999, desde diversos sectores se evaluó como insuficiente la calidad de la participación ciudadana en las políticas públicas. De este proceso dan cuenta, entre otros, Guillermo Campero en "Más allá del individualismo"; los documentos "Participación social en el Chile actual", de la Corporación Tiempo 2000 y "Renovar la Concertación: la fuerza de nuestras ideas"; el texto "Nuestros Miedos" de Norbert Lechner; los Informes del PNUD del año 1998 "Las paradojas de la modernización” y del año 2000 “Para Gobernar los Cambios"; y los trabajos de Claudia Serrano realizados para MIDEPLAN, la Secretaría General de Gobierno y SERNAM.

Estos documentos coinciden en levantar un diagnóstico crítico: a) nuestra sociedad no favorece ni impulsa la confianza y la construcción de lazos de cooperación, b) el esquema institucional y las políticas sociales no han promovido una participación ciudadana efectiva y decisional, sino más bien instrumental, c) la gente anhela y requiere más asociacionismo y capital social, d) existe una creciente y preocupante distancia entre la acción pública y la sociedad civil.

Los antecedentes recolectados, complementados con una experiencia empírica realizada, en el contexto de la investigación en la comuna de Rancagua, Sexta Región de Chile, realizada por quien expone estas ideas ${ }^{\mathbf{1}}$, se pueden afirmar antecedentes que validan lo expuesto con anterioridad:

Desde el ámbito interno de la Estructura del Estado, se requiere de una estructura organizacional adaptable y/o flexible a las

1 Percepción de los dirigentes vecinales respecto del modelo de descentralización municipal implementado por el municipio de Rancagua entre los años 1997 y 2003. investigación conducente a la obtención del grado de magíster en Políticas Sociales y gestión de la Universidad ARCIS. Además dicha experiencia fue premiada por el centro de Políticas Públicas de la Universidad de Chile y la Fundación para la Superación de la Pobreza en el año 1999, como un diseño de trabajo innovativo en lo que respecta a sus aportes en la construcción de ciudadanía. 
dinámicas sociales, es decir, se requiere de una visión / proyecto político que oriente y genere las directrices de trabajo hacia los territorios, involucrando en este proceso no sólo a la actividad "social" del municipio, sino a los propios sujetos y/o colectivos representantes de la sociedad civil, dado que son estos los principales protagonistas en la construcción de los procesos de desarrollo.

Se ve prioritaria la necesidad de involucrar como protagonistas a los diversos actores de la comuna. Es importante, por lo tanto, generar una visión de totalidad tanto de los actores locales, como del territorio, no parcelando o dividiendo a la sociedad ni a la comuna, sino creando una complementariedad de las fuerzas vivas en la consecución del desarrollo local. En este sentido, la relación entre ciudadanía y gobierno local se debería basar principalmente, en un vínculo colaborativo, donde ambos actores complementan sus roles, incorporando una visión más amplia de la gestión territorial.

Compartiendo el diagnóstico de una manifiesta debilidad de la participación ciudadana en Chile, otros autores sostienen que esta es expresión de un tránsito desde una participación centrada en el Estado y en temas reivindicativos relacionados con la igualdad y la justicia, a otros de carácter cultural, por ejemplo, las mujeres, el medio ambiente, las minorías étnicas, la identidad sexual, etcétera, temas que no interpelan exclusivamente al Estado, pero que reclaman de éste respuestas a modo de políticas públicas.

Ante estos nuevos escenarios la ciudadanía empieza a asumir paulatinamentenuevosrumbos, intentandoromperladependencia y manipulación estatal; si bien existe una intencionalidad política de mejorar las administraciones públicas en el contexto de la modernización del Estado, en forma paralela se están generando nuevos movimientos sociales que permiten a la ciudadanía posicionarse como un actor alternativo a los ya tradicionales. " $\mathrm{La}$ ciudadanía ya no es definida como pertenencia del individuo al Estado, sino como complejo de derechos - deberes de los sujetos de ciudadanía, ya sean individuos o actores colectivos" (Herrera 1996: 73)

En este sentido, la sociedad civil empieza a emerger dada la incapacidad que ha manifestado el Estado de asumir nuevos temas públicos y de interés ciudadano; emergen actores con capacidades de poder plantear nuevos desafíos y romper la lógica paradigmática del Estado a partir de sus tradicionales 
políticas sociales. "La mayor parte de los analistas del Estado de bienestar asumen posiciones defensivas y ven los cambios como una amenaza a las garantías sociales conquistadas en el pasado" (Herrera 1996:76).

En palabras de H. Arendt, el núcleo de la participación es el poder, y por ello supone la capacidad humana de actuar en concierto; el poder en este sentido, no es nunca la propiedad de un individuo, sino que pertenece al grupo y existe solo mientras este exista. La esfera pública alude al espacio donde los ciudadanos interactúan mediante los recursos del discurso y la persuasión, descubren sus identidades y deciden, mediante la deliberación colectiva, acerca de los temas de interés común (Arendt; 1993).

Es necesario, a partir de los escenarios expuestos, establecer relaciones horizontales entre los actores que son parte de los procesos de desarrollo del País, sociedad civil, mercado y Estado, intentando comprender la diferenciación entre éstos, de acuerdo a las propias características y necesidades, como el complemento para el logro de objetivos tanto individuales como colectivos.

Cabe mencionar además, la relevancia histórica, pues tener un conocimiento de este tipo de organizaciones nos puede permitir comprender su rol en momentos sociopolíticos claves en el desarrollo de nuestro país; es así que durante la década de los ochenta, las organizaciones de la sociedad civil contribuyeron de manera prominente a reconstruir los tejidos sociales, legitimándose dentro de los sectores populares; “junto a los campesinos, mujeres, jóvenes, obreros y pobladores, discutieron los problemas del país y elaboraron proyectos para un desarrollo diversificado y participativo de las comunidades locales" (Salazar 2003:23).

El retorno a la democracia fue quizás, en buena medida, producto del trabajo silencioso de la educación popular y de reconstrucción de tejidos sociales a lo largo y ancho de Chile, realizado durante esos años por las OTS; allí se discutieron los problemas laborales, los asuntos económicos, la cuestión de la mujer, los temas urbanos, la cuestión campesina, étnica, la pobreza, en fin, casi todos los temas más urgentes que vivió nuestro país en la época de la dictadura militar.

El Trabajo Social nace profesionalmente, por la necesidad de resolver problemáticas desprendidas de la desigualdad histórica, sus campos de actuación se pueden situar desde el ámbito 
público como también desde el ámbito de las organizaciones que representan a la sociedad civil.

\section{¿Qué es el tercer sector?}

Hablar del tercer sector nos lleva a una serie de conceptos que se han ido abordando según los contextos en que éste se desarrolla y la visión de sus autores; es así como nos encontramos con diferentes aproximaciones ante un mismo tema: organizaciones de la sociedad civil, sociedad civil organizada, tercer sector, organizaciones sociales y/o comunitarias, organizaciones vinculadas al voluntariado, a la prestación de servicios sociales, etcétera. Para ello, se darán conocer diferentes miradas del concepto para luego unificar criterios en torno a éste.

Es necesario iniciar la discusión desde una mirada histórica del concepto situándonos desde la época de Aristóteles, quién señala que el concepto de sociedad civil se ha vinculado en forma directa con el Estado, "la Polis", entiendo por ésta, aquella forma de organización social que permite establecer la relación entre los ciudadanos. En este sentido, la Polis es entendida como aquella forma "perfecta y autosuficiente de asociación humana, que se orienta no a la satisfacción de las necesidades, sino a la vida buena" (Botella, 1998:41).

Lo anterior nos permite comprender que desde aquella época ha existido la necesidad de establecer el vínculo entre el ciudadano y el Estado, como forma de buscar una convivencia que permita lograr el bien común. Esta convivencia es fundamental para lograr dar respuesta tanto al interés del Estado, como de los propios ciudadanos. En esta línea, es necesaria la búsqueda de la horizontalidad en la relación, es decir, un vínculo que potencie la participación activa de ambos actores en los procesos de desarrollo de un territorio.

El desafío está en poder entender el concepto de participación, dado que éste puede diferir de un territorio a otro, por ende el concepto será diferente según las características sociopolíticas, afectando el tipo de relación entre los actores, como por ejemplo, subordinación en la toma de decisiones. "Por ello, el significado se define por su participación en la administración de justicia y en el gobierno. $\mathrm{Ni}$ el hecho de residir en un lugar ni el de descender de ciudadanos bastan para obtener la condición de tal, que finalmente viene determinada por la constitución de la Polis." (Botella, 1998:41) 
Es fundamental, siguiendo a Aristóteles, que el sentido del ciudadano en un territorio depende del proyecto político que emana del gobierno como ente representante del Estado, por ende el ser ciudadano o sentirse tal, depende de las directrices sociopolíticas establecidas por un gobierno donde se respeten los derechos y deberes: "gobernar y ser gobernados" (Botella, 1998:41).

Según Aristóteles, la perfección del hombre se cumple en la ciudad; en su condición de ciudadano libre, en este sentido su famosa definición del hombre como un "ser cívico por naturaleza (zoon politikón); el hombre es por naturaleza un animal de ciudad, un animal cívico" (García 1997:28). Ahí el ser cívico del hombre se hace político, en cuanto participa del gobierno de los asuntos de la colectividad. Los ciudadanos no están al servicio del Estado, ellos mismos son el Estado. La Polis es el conjunto de los ciudadanos. Por eso politeía significa tanto "constitución de política" como "ciudadanía". Y no se dice la "constitución de Atenas; sino la "constitución de los atenienses". (García 1997:29).

El tema en cuestión y que también era la discusión de aquella época, son aquellas personas derechos ciudadanos son restringidos y no pueden ser parte de la vida política, por ejemplo los esclavos, o bien quienes tenían una renta sólida, comerciantes, artesanos, según la lógica aristotélica, tiene sentido hoy en día, donde por definición todas las personas de un territorio son ciudadanos con deberes y derechos, pero el asunto se restringe cuando esos derechos son vulnerados y no son considerados en la relación con el Estado, tema no menor que nos permite comprender conceptos que han ido evolucionando con el tiempo: marginados, vulnerados, excluidos.

En esa "vida política y cívica donde el Estado no tiene organismos propios y donde no hay delegación de la participación ciudadana en las grandes cuestiones de gobierno, el ciudadano libre actúa a sus anchas como individuo y se siente un elemento imprescindible de la ciudad" (García 1997: 30).

Donati (1997) plantea que es necesario situarse desde qué posición se define el tercer sector; el autor señala que se puede realizar un análisis desde una mirada externa, que en términos generales, señala el punto de vista de los otros actores, sistemas o instituciones, realizando una definición del tercer sector desde fuera de éste; es así como nos encontramos con reflexiones que 
apuntan a definir el tercer sector como el producto y posible remedio de la crisis del Estado del Bienestar, definiéndolo en sí desde una prisma negativo, haciendo alusión por ejemplo a la exclusión: aquello que no es el Estado ni el Mercado.

En este mismo sentido, Herrera (1998) señala que el concepto es visto desde una connotación negativa: "que es un sector constituido por organizaciones que no son públicas y no son de mercado, sino que lo identifica como un sector residual que contiene aquellas organizaciones que no se engloban ni en el Estado, ni en el mercado; el hecho de subrayar el carácter "tercero" del fenómeno configura el propio referente empírico por negación" (Herrera 1998:163).

Siguiendo esta misma línea, Acotto (2003) señala que la nominación de tercer sector está dada desde lo que no son, y constituye una postura excluyente; las organizaciones de una sociedad que no están en el primer sector (Estado) ni en el segundo (empresas) caen el tercero (organizaciones sin fines de lucro) por peso específico, sin muchas más claridades ni consideraciones al respecto.

Bajo esta misma lógica y profundizando la otra mirada "interna" de las organizaciones de la sociedad civil, Acotto (2003) señala que "son organizaciones conformadas por personas que se nuclean en grupos estructurados en base a normas, intereses, objetivos y fines particulares que tienden a dar respuestas a necesidades sociales grupales y colectivas" (Acotto, 2003:14). En definitiva, son organizaciones que nacen producto de la incapacidad del Estado de dar respuesta a las múltiples problemáticas que se van generando en los países, por ende, surge la necesidad de que sea la propia comunidad, que en forma organizada, desarrolle sus capacidades para abordar aquellas situaciones donde el Estado no ha llegado. En sí mismas las organizaciones de la sociedad civil, son el conjunto de personas que en forma colectiva intentan generar procesos de desarrollo en función de sus necesidades e intereses; el protagonismo es dado a partir de los propios actores involucrados, quienes a partir de sus procesos de cohesión logran cumplir sus objetivos o metas.

Otra mirada la da, Arbos y Giner (1993), quienes señalan que en sociedades menos desarrolladas, no occidentales, carecen por completo de sociedad civil, se define la Sociedad civil "como una esfera, creada históricamente, de derechos individuales y asociaciones voluntarias, en la que la concurrencia políticamente 
pacífica de unos con otros en la persecución de sus respectivos asuntos, intereses e intenciones privadas, está garantizada por una institución pública, llamada Estado." (Arbos y Giner 1993: 23).

Desde otra perspectiva Buqueras y Bach (2002) las definen, en palabras de Cabra de Luna, como "el conjunto de entidades no lucrativas o de carácter solidario que vienen a complementar, cuando no a sustituir, a las actividades de interés general llevadas a cabo, con distinta suerte, con anterioridad por el Estado, según el grado de desarrollo económico y modernización de cada país." (Buqueras y Bach 2002:95). Este punto es fundamental, dado que en América Latina y específicamente en Chile, el tercer sector se ha caracterizado por dar un avance en términos cuantitativos, es decir, ha existido en este último una cantidad importante de organizaciones de la sociedad civil que emergen en función de las diferentes problemáticas de nuestro país, movimientos medio-ambientales, grupos étnicos, minorías sexuales, etcétera, y que de alguna u otra manera intentan demandar al Estado el conjunto de necesidades insatisfechas. Esta apreciación coincide con lo expuesto por Acotto (2003), desde la mirada de la realidad de Argentina, quien señala "que en América Latina el modelo de organizaciones de la sociedad civil difiere sustancialmente del modelo existente en Europa y Estados Unidos, que han liderado el proceso de desarrollo de las organizaciones de la sociedad civil. El modelo latino es un modelo de crecimiento cuantitativo más que de crecimiento cualitativo, vinculado a la pobreza, a la violencia de Estado, a la pérdida de derechos civiles, sociales económicos, políticos, etcétera." (Acotto 2003:14).

También Herrera (1998) nos señala que las organizaciones del tercer sector "son un sujeto social compuesto por un conjunto de personas que comparten y participan de una relación que es sentida, vista y actuada como referente simbólico-intencional, donde los sujetos son vistos como una realidad relacional, hecha de relaciones o redes que conectan intersubjetiva y estructuralmente" (Herrera 1998:165).

En definitiva lo planteado por los diversos autores antes expuestos, insta a comprender al tercer sector, sociedad civil, organizaciones de la sociedad civil o del tercer sector, como actores que surgen de la necesidad de poder dar respuesta a aquellas situaciones en que ni el Estado ni el Mercado han sido capaces de dar respuesta a aquellos sectores que se sienten insatisfechos en 
estos nuevos escenarios. Por ende, entender al tercer sector, es pensar en actores que tienen sus propias dinámicas internas, con objetivos diversos, capacidades y potencialidades de articularse con otros actores, que son parte del territorio. Así, es necesario validar la complementariedad entre la sociedad civil, el Estado y el mercado, para dar respuesta a las múltiples necesidades de los diferentes sujetos que son parte de un territorio.

En este sentido, es necesario que la horizontalidad sea entendida como la capacidad política que debe tener el Estado para interlocutar con otros de igual a igual, lo que es necesario para dar respuesta a las nuevas problemáticas sociales. Es decir, un Estado con capacidad de articular y coordinar iniciativas públicas, con el apoyo de otros actores, que permita la democratización de los procesos sociales donde es indispensable traspasar cuotas de poder a otros, para que en forma colectiva, se aborden situaciones desde la diversidad y no desde una mirada unilateral. Como complemento a esta relación, es necesario contar con una sociedad civil con capacidades de abordar estos nuevos desafíos, con capacidad crítica y a su vez propositiva.

\section{Características y/o funciones de las organizaciones de la sociedad civil}

Según esta revisión bibliográfica, existen diferentes características que de alguna otra manera nos permiten comprender mejor a las organizaciones de la sociedad civil. En este sentido, daremos a conocer las principales características atribuidas por distintos autores, para posteriormente realizar en el análisis relacional de cada una de ellas:

Acotto (2003) señala algunas características de las organizaciones del tercer sector:

- Son privadas: están constituidas por el derecho privado, aun cuando utilicen en muchos casos fondos públicos y desarrollen acciones de políticas públicas, generalmente son descentralizadas por el Estado. Desde esta perspectiva, es necesario establecer que de acuerdo a las diferentes aproximaciones conceptuales dadas en el apartado anterior es que estas pertenecen al mundo de lo privado, no son parte del Estado ni del mercado, si bien éstas se relacionan o existe un vínculo funcional, son parte de la dimensión de lo no público y funcionan principalmente en los niveles sub-nacionales. 
Es decir, ejecutando las políticas sociales a nivel local, obviamente a partir de los fondos entregados por el Estado, pero que mantienen su calidad de no gubernamentales.

- Otra característica a mencionar es que son auto-gobernadas: determinan su forma de gobierno y sus mecanismos de funcionamiento, a través de sus estatutos y reglamentaciones internas; se gobiernan a sí mismas. En este sentido, podemos decir que desde su propia dinámica interna son organizaciones que poseen autonomía en las formas de funcionamiento de acuerdo al contexto legal en el cual se sitúen. Es decir, presentan su propia estructura organizativa según los objetivos y fines que persiga, siendo éstos lícitos.

- Además la autora señala que son no lucrativas, es decir, no constituyen ganancias o lucro entre sus miembros. Lo cual no significa que no abonen sueldos, o el trabajo sea no remunerado, es decir, si bien existe un trabajo remunerativo, las ganancias en el ejercicio económico, son redistribuidas en el propio trabajo y no entre sus miembros.

Por último a estas características hay que agregarles las que menciona el código civil para que puedan funcionar:

- Tener como principal objeto el bien común

- Poseer patrimonio propio

- Ser capaces por sus estatutos de adquirir bienes

- No subsistir exclusivamente de asignaciones del Estado

También Acotto (2003) agrega que algunos autores suman otras características no compartidas por todos, pero que son importantes de considerar y no descalificar:

- No están destinadas a la transmisión de un culto o credo religioso, y

- No tienen identificación político-partidaria

Por otro lado, Herrera (1998) señala que las organizaciones del tercer sector se "identifican con el voluntariado, personas que se comprometen gratuitamente para asistir a pobres, ancianos, minusválidos, enfermos, etcétera, para proteger el ambiente, para socorrer a poblaciones que han sufrido desastres naturales, para organizar actividades deportivas o para promover iniciativas culturales" (Herrera 1998: 163). Es decir, la presencia de voluntarios en las organizaciones del tercer sector, es una distinción muy clara respecto a las organizaciones de mercado, ya que en estas últimas, la misma legislación no prevé la posibilidad de 
colaboraciones gratuitas. Parece menos discriminante respecto a las organizaciones públicas, en cuanto que en éstas es posible desempeñar o realizar trabajo voluntario. Sin embargo, se considera que en las organizaciones públicas, el voluntariado se configura como un rol accesorio y opcional, en el sentido de que pueden cubrir tareas institucionalmente asignadas a la organización, y que su presencia no puede jamás ser considerada indispensable o necesaria.

Desde otro punto de vista, existe la confusión que las Organizaciones de la Sociedad Civil, solamente se vinculan a acciones de caridad y/o de beneficencia, situación que en la actualidad es tener una visión parcial de éstas. Siguiendo a Herrera (1998), se debe considerar que también son organizaciones que constituyen un campo de actividades que a menudo sirve para entrar en el mundo profesional. Son organizaciones que tienen la necesidad de un cierto cálculo económico (por tanto, usan dinero y otros medios de mercado) y tienen la obligación de adecuarse a normas legales (condiciones puestas por el Estado).

Es en este contexto que las Organizaciones de la sociedad civil entran en el área de las intervenciones, que apuntan no solo a la "asistencialidad" y, no desconociendo ésta, también entran el ámbito de las intervenciones que apuntan a generar procesos de cambio, optando por metodologías propias de las Ciencias Sociales.

Herrera (1998) señala que estudios realizados por M. Ambrosini (1994) apuntan a establecer algunos rasgos distintivos de las organizaciones de la sociedad civil, entre ellas menciona:

Las actividades realizadas son variadísimas, desde la asistencialidad, hasta actividades comerciales del todo similares a las normalmente realizadas por empresas de mercado, agrupando esta variedad en cinco grandes sectores de intervención: el sector socio - asistencial, el de educación y la animación sociocultural, el de defensa ambiental y el de protección civil.

La misma variabilidad hace que su composición sea a partir de trabajadores técnicos o profesionales pagados, además de contar con un aporte no menor de voluntarios para ejecutar sus diversos programas.

Por otro lado, encontramos las fuentes de ingresos, siendo éstas diversas, procedentes del sector público, ingresos provenientes 
de la venta de bienes y servicios, ingresos procedentes de las donaciones, ingresos a partir de las cuotas asociativas, etcétera.

Otra característica que señala Herrera (1998) apunta al trabajo colaborativo, es decir, existen organizaciones de la sociedad civil que trabajan en forma colaborativa con el sector público estatal, mientras que otras actúan de manera completamente autónoma.

Además, se puede mencionar que el producto que persiguen las organizaciones de la sociedad civil, está más configurado no desde un bien, ni de una ley o reglamento, sino el cambio en la persona, son instituciones que procesan personas en cuanto agentes de cambio.

Otra característica fundamental de las Organizaciones del tercer sector, es que son "expresivas de valores", esto implica que el modo en que actúan y/o el tipo de relaciones que circulan está íntimamente conectado a los valores que tales organizaciones representan.

Para Donati, en Herrera (1998), el tercer sector debe ser leído como:

- Un modo de ser positivo y propositivo de la sociedad (antes que como un tipo de relaciones sociales que se difunden por reacción negativa o por salida respecto a otras relaciones o instituciones).

- Una forma social emergente que nace de la exigencia de diversificar las respuestas a específicas necesidades sociales, que siguen dinámicas de descomposición y multiplicación y que siempre solicitan nuevos relacionamientos.

En definitiva Donati en Herrera (1998), señala que el tercer sector y sus organizaciones deben ser comprendidos y explicados como producto de la diferenciación societaria en condiciones de creciente complejidad social.

\section{Conclusiones}

Según lo planteado, se puede señalar la necesidad de conjugar dos dinámicas que potencien la relación entre las organizaciones del tercer sector y el Estado, que según Palma (2002); se refiere a que es "una particular relación que surge (o que puede surgir) en el encuentro de dos dinámicas: una es la capacidad de participar, 
que son las aptitudes, habilidades y recursos que los sectores llamados a incorporarse en esta empresa común, han venido acumulando a través de sus prácticas y reflexiones y que se vincula con la categoría tercer sector.

Es así que los representantes de las organizaciones del tercer sector señalan como área a mejorar, el contar con opinión pública en la región. Es decir, desde su propia actoría, tener la capacidad de relevar temáticas sociales en la región, según la especificidad de cada organización, y de esta manera, ser un actor que pueda aportar e interlocutar con el Estado no tan solo cuando se está ejecutando la política social, sino también al momento de diseñar dicha política.

Desde la dimensión capacidad, también podemos concluir como área a mejorar, el significado que estas organizaciones adquieren para el resto de la sociedad civil. Es decir, son las organizaciones del tercer sector las llamadas a representar los intereses ciudadanos, sin embargo, en la Sexta Región de Chile, ninguna de éstas organizaciones genera los espacios de interlocución para poder representar los intereses de la comunidad. Existe una ruptura entre estas organizaciones y la ciudadanía en general.

Otro elemento a resaltar es la escasa articulación que se da entre las organizaciones del tercer sector. Es decir, tampoco existen los espacios para lograr un trabajo articulado entre las diferentes organizaciones de la Región, más bien, cada una de éstas actúa en forma autónoma, en pequeñas parcelas que dificultan, o bien, son un obstáculo para generar opinión pública en la Región. Esta situación también conlleva que no existen metodologías de trabajo que sean sistematizadas y compartidas con otras organizaciones de la región, por tanto, el no contar con dichos espacios dificulta la elaboración de los fundamentos teóricos que respalden las visiones de la sociedad civil.

Es importante que estas organizaciones logren articular un trabajo desde la propia realidad social, como un conjunto de actores que pueden definir o redefinir acciones estratégicas emanadas desde el mismo Estado. Desde esta lógica se requiere de una sociedad civil fortalecida, que genere aportes desde la propia actoría social, desde su cúmulo de experiencias, desde su propia historia, gestión y trabajo territorial. Lo anterior, permitiría dialogar con las instituciones locales al momento de tomar decisiones que involucren a la realidad regional. 
De acuerdo a lo anterior, es necesario que las organizaciones del tercer sector puedan articular redes de apoyo desde el sector privado. Es decir, posicionar como lineamientos estratégicos, la generación de espacios con otros actores, para que en forma colectiva se asuman los desafíos pendientes: Estado - sociedad civil - empresas.

Asimismo, es fundamental que desde la propia estructura de éstas se pueda asumir la relevancia de generar recursos, no solamente desde las distintas fuentes de financiamiento que entrega el Estado, sino más bien contar con la capacidad y las oportunidades que entrega el marco regulatorio legal del país, a partir de la responsabilidad social empresarial. Situación que permitiría ampliar dichas fuentes de financiamiento, rompiendo de esta manera la instrumentalización con el Estado, permitiendo además la creación de nuevas instancias de intervención.

También es necesario mencionar que cada organización del tercer sector presenta debilidades en sus estructuras organizacionales. Es decir, actualmente su funcionamiento es producto de un número reducido de personas que son parte del directorio y privilegian su actuar en función de sus tiempos e intereses. No existe un grupo de profesionales o voluntarios que puedan abrir nuevas alternativas de trabajo, de acuerdo a los diversos campos problemáticos que se vivencian en la Región.

Las organizaciones del tercer sector señalan con claridad la necesidad de generar espacios de reflexión y análisis de su propio actuar en la región, donde puedan relevar temas que apunten a fortalecer el accionar de estas organizaciones, donde se pueda trabajar y fortalecer las intervenciones que se desarrollan en cada uno de los contextos. Pero por sobre todo, contar con opinión pública respecto de las temáticas más sentidas en la Región.

Lo expuesto puede permitir interlocutar con el Estado en una relación de horizontalidad generada producto de la experiencia y legitimación ante la generación de conocimientos de la propia realidad. Esto implica un mínimo de organización entre las organizaciones del tercer sector, para potenciar espacios que permitan colectivizar sus organizaciones en una instancia que recoja y/o agrupe a la diversidad de ellas, para así constituirse como interlocutores válidos ante el Estado.

Por otro lado, podemos mencionar otra dimensión que está íntimamente relacionada con la anterior, que es la oportunidad de 
participar. Ahora estamos mirando al Estado como responsable en el diseño de la política social, pues éste debiera permitir el ejercicio de la capacidad participativa. Podemos hablar de participación cuando se ha provocado una adecuación entre estas dos dinámicas. Esto quiere decir que por un lado se requiere de organizaciones del tercer sector fortalecidas, con capacidad de plantear propuestas pero a su vez, se requiere la generación de espacios para poder interlocutar entre actores Estado - sociedad civil.

En la construcción de ciudadanía donde los diferentes actores asumen un rol relevante, se requiere, en el caso de la realidad chilena, que el Estado genere las aperturas, oportunidades, la voluntad política de ceder cuotas de poder al momento de interlocutar con otros actores, es decir, además de contar con organizaciones del tercer sector capacitadas desde su propia dinámica, se requiere en toda relación la disposición de quien detenta el poder, de democratizar esa relación.

Los representantes de las organizaciones del tercer sector perciben que dicha relación no se ha logrado, pues quienes diseñan las políticas sociales a nivel nacional, son los propios entes representativos de la misma estructura del Estado, donde otros sectores no son parte del proceso. En el caso de las organizaciones del tercer sector, son los responsables solamente de ejecutar dicha política a nivel regional.

Lo anterior significa que no existe un acercamiento real de las decisiones públicas a la sociedad civil; se mantiene la lógica de un Estado centralizado, donde la ciudadanía es solamente receptora de beneficios sociales.

En relación a la descentralización del Estado, bajo el prisma que interesa en este estudio, que es la "democratización de los procesos sociales", se puede concluir que los representantes de las organizaciones del tercer sector vinculan el concepto solamente al traspaso de recursos, mientras más recursos cuenten las regiones, se entiende que el país es más descentralizado, situación que puede agudizar e instrumentalizar la relación, a partir solamente de la asignación de recursos.

En este mismo punto el Estado, al actuar bajo el modelo centralizado y jerárquico en su relación con los niveles subnacionales, hace que a nivel regional las intervenciones realizadas por las organizaciones del tercer sector, no sea acorde a la realidad, 
ni a los tiempos de su población objetivo, como además, a las dinámicas propias de sus respectivas organizaciones, dejando muchas de ellas de funcionar.

Vinculado a la temática de la descentralización se puede señalar que lo anterior también es producto de que el Estado ha visto con dificultad la posibilidad de implementar el proceso modernizador de su gestión, no contando a nivel regional con los recursos y funcionarios para cumplir los desafíos que se esperan en la relación con la sociedad civil, puntualmente de dar seguimiento y control al uso de recursos públicos asegurando la transparencia y probidad en el uso de éstos.

Lo anterior potencia que los representantes de las organizaciones del tercer sector perciban que el Estado está privatizando sus servicios sociales, dado que éste no está en condiciones de asumir tales responsabilidades y que requiere, necesariamente, del apoyo de otros para lograr concretar las políticas sociales a nivel local.

En definitiva estas reflexiones preliminares dejan abierta la discusión respecto a la temática en estudio.

\section{Referencias bibliográficas}

ACOTTO, L. (2003). Las organizaciones de la sociedad civil; un camino para la construcción de ciudadanía.Buenos Aires: Espacio.

ARBOS X. y GINER S. (1993). Corporativismo y gobernabilidad. En Arbos X. y Giner S. La gobernabilidad: ciudadanía y democracia en la encrucijada mundial (capitulo 3). Madrid: Siglo XXI.

BOTELLA, J. y CAÑEQUE C. (1998). El pensamiento político en sus textos de Platón a Marx. Madrid: Tecnos.

BUQUERAS y BACH, I. (2002). El Tercer sector en_España. En Buqueras Más sociedad, menor y mejor Estado pasado, presente y futuro de la sociedad civil (capitulo V). Madrid: Complutense.

DONATI P. (1997). El desarrollo de las organizaciones del tercer sector en el proceso de modernización y mas allá. REIS, (79), pp. 113-142.

GARCÍA GUAL, C. (1997). Aristóteles Política. Madrid: Espasa Calpe.

HERRERA, M. (1996). Las Políticas Sociales en el Welfare Mix. REIS, 96(01), pp.71-93. 
(1998). La especificidad organizativa del tercer sector: Tipos y dinámicas. Papers (56), pp. 163-196.

IGLESIAS DE URSEL, J. (2004). Bienestar Social una aproximación teórica. Sociedad Civil y estado de Bienestar. En Herrera, M y Trinidad, A. (Coord.) Administración Pública y Estado de Bienestar. Madrid: Thomson civitas.

IRARRÁZABAL, I; HAIREL, H; SOKOLOWSKI, W; SALAMON, L. (2006). Estudio Comparativo del Sector Sin Fines de Lucro. Santiago, Chile: PNUD.

SALAZAR, G. (2003). La larga y angosta historia de la solidaridad social bajo régimen liberal (Chile, siglos XIX y XX). (Cuadernos de Historia 23). Santiago, Chile: Universidad de Chile.

SERRANO, C. y VICHERAT, D. (2008). ¿Qué motiva a la gente a actuar en común. Estudio sobre la participación en la población Malaquiás Concha comuna de la Granja. Santiago, Chile: Cieplan. 